Research Article

\title{
Benefit Analysis of Low-Carbon Policy Mix Innovation Based on Consumer Perspective in Smart City
}

\author{
Wenjie Chen $\left(\mathbb{D},{ }^{1}\right.$ Xiaogang Wu $\left(\mathbb{D},{ }^{1}\right.$ and Ngabo Desire $\mathbb{D i D}^{2}$ \\ ${ }^{1}$ Business College, Central South University of Forestry and Technology, Changsha 410004, China \\ ${ }^{2}$ African Center of Excellence in the Internet of Things, University of Rwanda, Kigali, P.O. Box 3900, Rwanda \\ Correspondence should be addressed to Wenjie Chen; t20142193@csuft.edu.cn
}

Received 18 August 2021; Accepted 5 October 2021; Published 14 October 2021

Academic Editor: Zhu Xiao

Copyright (c) 2021 Wenjie Chen et al. This is an open access article distributed under the Creative Commons Attribution License, which permits unrestricted use, distribution, and reproduction in any medium, provided the original work is properly cited.

In the construction of smart city, the carbon emission reduction problem of road traffic needs to be solved urgently. It is of great significance to introduce reasonable low-carbon policies. Based on urban private cars trajectory data, this study, respectively, establishes the genetic algorithm-back propagation neural network model (GA-BP) and back propagation-adaptive boosting algorithm neural network model (BP-AdaBoost) to predict the carbon emissions of private cars. By comparing the two neural network models, the GA-BP neural network model has better prediction results. Next, this study establishes the cost-benefit model for consumers and compares consumers' participation willingness, emission reduction effect, and social benefits of consumers from the perspective of six kinds of low-carbon policies. The results show that the overall effect of the low-carbon policy mix of free quota is better than that of paid quota. In addition, different low-carbon policy mixes innovations have different policy implementation effects under different indicators. Overall, the low-carbon policy mix of carbon trading and emission reduction subsidy is better in the short term, and the low-carbon policy mix of carbon tax and emission reduction subsidy is better in the long term.

\section{Introduction}

Road traffic is the fastest growing carbon emission source in the world, and the introduction of reasonable low-carbon policies has always been the focus of global attention. As early as 2013, China's Ministry of Transport proposed the introduction of the carbon-trading policy to promote green and low-carbon development of the transport sector. At present, many countries, such as Sweden and the UK, have introduced low-carbon policies to reduce carbon emissions in road traffic. Although China has introduced the carbontrading policy, the low-carbon policy mix of road traffic carbon emission reduction has not been put into practice. By March 2021, the number of motor vehicles in China have reached 378 million [1], and its carbon emissions have become the third largest source of carbon emissions in China, which poses a huge challenge to achieve carbon peak and carbon neutrality. This study combines private car data with low-carbon policy mix innovation to study effective emission reduction measures to promote sustainable development of smart city. First, the carbon emissions of private cars can be well predicted through deep learning of private car data. Next, according to the carbon emissions of private cars, government can introduce low-carbon policy mix innovation to achieve the emission reduction goal. In addition, road traffic is an indispensable part of smart city, and the effective emission reduction of road traffic is a necessary way for smart city to achieve sustainable development. Therefore, based on the urban private cars trajectory data, this study introduces low-carbon policies such as carbon quota allocation, carbon trading, carbon tax, and emission reduction subsidy, discusses the effect of policy implementation from the consumer perspective, and studies the feasibility and benefit of low-carbon policy mix innovation.

For the carbon quota allocation, current studies can be broadly divided into two categories: free quota and paid quota. As for the allocation of free quota, consumers can get 
a fixed amount of carbon emission for free. Chen and Liu proposed the allocation of free quota to help save energy, reduce emissions, and gain public recognition [2]. Pan and Shi put forward that the allocation of free quota is more intrinsically necessary than paid quota, which is conducive to play the role of emission reduction incentive [3]. Wei et al. believed that the implementation of free quota in the early stage of carbon market is better for the overall social welfare, but there are some defects in fairness and efficiency [4]. As for the allocation of paid quota, consumers need to conduct paid bidding to obtain the carbon credits. Zhang et al. believed that the income from paid quota can be used to set up carbon funds to promote low-carbon transition and development [5]. Miao proposed that the allocation of paid quota could reduce the cost of enterprise performance and meet the financing needs of enterprise [6]. Li argued that paid quota is a more effective way of resource allocation, which can not only encourage enterprises to reduce carbon emissions but also reapply the benefits to technological innovation [7]. In addition, some scholars believed that the paid quota and free quota have their advantages and disadvantages. Xuan and Zhang believed that free quota has little impact on social economy, but there are serious deficiencies in fairness and efficiency. Paid quota is easy to be monopolized by powerful industries in the process of quota auction [8]. Ding and Feng believed that free quota can reduce the production burden of enterprises, but the cost of emission reduction will be passed on to consumers. The paid quota will influence the profits of enterprises and affect their competitive position, but it is beneficial to form a transparent market price and reflect the marginal emission reduction cost of enterprises [9]. At present, the allocation of carbon quota adopts a mixed way and the transition from free quota to paid quota. $\mathrm{Hu}$ et al. proposed that single or mixed quota methods in different industries have a significant impact on the operating efficiency of carbon market [10]. Wu et al. showed that it is more beneficial to adopt different quota methods in the early stage of the carbon market establishment [11].

Different scholars have different views on market-based low-carbon policies such as carbon tax, carbon trading, and emission reduction subsidy. For the study of carbon tax policy, the vast majority of scholars agree that carbon tax policy is effective. Shikha and Aditi showed that carbon tax policy is a flexible and effective tool for reducing emissions by building a sustainable inventory model [12]. Baranzini et al. believed that the carbon tax policy can obtain implicit benefits, and its negative effects can be offset by tax design. However, some scholars believe that the effect of carbon tax policy is not significant [13]. Botteon and Carraro argued that there is no evidence that carbon tax policy would significantly reduce carbon emissions [14]. Li et al. showed that carbon tax policy could not achieve the effect of reducing carbon emissions and growing double dividend in the short term [15]. In terms of the carbon-trading policy, most scholars have demonstrated the effectiveness of the carbon-trading policy in reducing emissions and increasing social benefits through empirical studies $[16,17]$. The carbon trading price and the allocation of carbon quota will significantly affect the emission reduction effect of the carbon-trading policy. With the introduction of the emission reduction subsidy policy, most scholars have shown the synergistic and emission reduction effects of the emission reduction subsidy policy. He and Yue found that using low-intensity environmental technology subsidies could reduce the emission reduction costs of enterprise and improve environmental quality [18]. Wang et al. showed that the combination of carbon tax and emission reduction subsidy could produce greater emission reduction, and the emission reduction policy should gradually shift from carbon tax to emission reduction subsidy [19]. Based on the above research, in order to better arrange the policy mix innovation, this study subdivides the low-carbon policy mix into two categories. One is command-and-control type, including free quota allocation and paid quota allocation. The other is market-based type, including carbon tax, carbon trading, and emission reduction subsidy. The command-and-control low-carbon policy means that the government restricts environmental pollution through regulations and other means. The market-based low-carbon policy guides consumers to reduce pollution levels through market mechanisms.

In addition, low-carbon policy mix, compared with single low-carbon policy, can produce a better emission reduction effect and social welfare. Diao et al. proposed that the low-carbon policy mix could promote the improvement of the optimal emission reduction rate of low-carbon products [20]. Wang et al. proposed that low-carbon policy mix could expand the emission reduction boundary of the supply chain and save the implementation cost of the government [21]. With the development of low-carbon policy mix theory, scholars further proposed policy mix innovation. Policy mix is dynamic, and the interaction of policy mix is the core content of policy mix innovation [22]. The innovative characteristics of policy mix include uniformity, coherence, trustworthiness, comprehensiveness, and sufficiency [23]. Some scholars also proposed that the innovation characteristics of the policy mix are reflected in the governance space and policy space $[24,25]$. The use of the policy mix in low-carbon innovation is increasingly significant. Karoline and Schleich proposed that policy mix innovation is positively correlated with the innovation expenditure of renewable energy, and policy mix innovation should pay more attention to low-carbon and ecological innovation in the future [26]. Costantini et al. proposed that the limited policy mix would reduce the effectiveness of policies, and only comprehensive policy mix innovation can produce energy-saving and environmental protection technologies [27]. In addition, in terms of green and lowcarbon urban development, the construction of smart city is also an important part. Chu et al. proposed that smart cities could reduce pollution and improve the quality of ecological environment [28]. Shi et al. pointed out that smart city construction can effectively reduce urban environmental pollution through innovation drive [29]. As an indispensable part of smart city construction, road traffic should pay more attention to policy mix innovation [30]. Therefore, when introducing carbon reduction policies for road traffic, China can consider introducing single or mixed low-carbon 
policies in different periods to achieve the optimal emission reduction effect. At present, there are few literatures about the introduction of the low-carbon policy into the carbon emission reduction of road traffic, and empirical research literature is scarce too. Therefore, this study introduces the low-carbon policy into the carbon emission reduction of private cars and conducts quantitative analysis based on the perspective of consumers. The remainder of this study is organized as follows. Section 2 establishes the comparison model of the GA-BP neural network and BP-AdaBoost neural network and the cost-benefit model of consumer. Section 3 compares the prediction results between the GABP neural network model and BP-ADA neural network model. Section 4 compares and analyzes the implementation effect of the low-carbon policy mix from the consumer perspective. Section 5 draws conclusions and gives proposals.

\section{Materials and Methods}

Based on urban private cars trajectory data, this study establishes the BP neural network model optimized by GA and the BP neural network model optimized by the AdaBoost algorithm. GA is a method to search for optimal solution by simulating the natural evolution process. The BP neural network is a multilayer feedforward neural network trained according to the error back propagation algorithm. The GA$\mathrm{BP}$ algorithm is before the BP algorithm. GA is first used to inherit the initial optimization value in the random point set, which is used as the initial weight of the BP algorithm, and then trained by the BP algorithm. AdaBoost is an iterative algorithm. Its core idea is to train different classifiers (weak classifiers) for the same training set and then assemble these weak classifiers to form a stronger final classifier (strong classifier). The BP-AdaBoost algorithm takes the BP neural network as a weak classifier, trains the BP neural network repeatedly to predict sample output, and obtains a strong classifier composed of multiple BP neural network weak classifiers by the AdaBoost algorithm [31]. In this study, the mileage, travel time, and fuel consumption of private cars are taken as the predictive variables and carbon emissions as the target variables. RMSE, MAE, and error sum of the simulation results of the two models are used to judge the performance of the model. In addition, this study takes carbon emissions per unit mile as the standard of emission reduction subsidy. Consumers who exceed carbon emissions per unit mile cannot obtain emission reduction subsidies.

\subsection{GA-BP Neural Network Model and BP-AdaBoost Neural} Network Model. This study establishes a three-layer GA-BP neural network model and selects 10,000 urban private car trajectory data. The initialization genetic algorithm parameters are set as follows: the number of iterations is 30 ; the population size is 10 ; the crossover probability is 0.5 ; and the mutation probability is 0.1 [32]. In addition, the training error of the neural network is used as the fitness value of the genetic algorithm. This study adopts the roulette operation mode. The selected individual has a certain probability of passing on this fitness to the next generation, and the probability of each individual being selected is as follows:

$$
P_{i}=\frac{f_{i}}{\sum_{j=1}^{n} f_{j}},
$$

where $P_{i}$ is the probability of being selected, and $f_{i}$ is the individual fitness. Crossover operation is a random pairing of individuals within a population to exchange genes. The cross inheritance is as follows:

$$
\left\{\begin{array}{l}
C_{x i}=C_{x i}(1-a)+C_{y i} a, \\
C_{y i}=C_{y i}(1-a)+C_{x i} a,
\end{array}\right.
$$

where $C_{x i}$ is the cross-interchange of the $x^{\text {th }}$ chromosome at $i, C_{y i}$ is the cross-interchange of the $y^{\text {th }}$ chromosome at $i$, and $a$ is a random number from 0 to 1 . Mutation manipulation is the use of mutation probability to produce new genes. The genetic variation of the $i^{\text {th }}$ individual is as follows:

$$
\begin{aligned}
C_{i j} & =\left\{\begin{array}{l}
C_{i j}+\left(C_{i j}-C_{\text {max }}\right) * f(t) g>0.5, \\
C_{i j}+\left(C_{\text {min }}-C_{i j}\right) * f(t) g \leq 0.5,
\end{array}\right. \\
f(t) & =r\left(1-\frac{t}{t_{\max }}\right)^{2} .
\end{aligned}
$$

In the above formula, $C_{\max }$ is the maximum value of the gene, $C_{\min }$ is the minimum value of the gene, $C_{i j}$ is the $j$ gene of the $i^{\text {th }}$ individual, $g$ is the random number from 0 to $1, t$ is the number of iterations, $t_{\max }$ is the maximum number of iterations, and $r$ is the random number. The algorithm solves the optimal weight and threshold by iteration and assigns the optimal initial threshold and weight to the BP neural network model for prediction.

The BP-AdaBoost neural network model established in this study is also a three-layer neural network structure. The initial sample data weight is $1 / 7000$. The prediction error and prediction weight obtained by BP neural network training are as follows:

$$
\left\{\begin{array}{l}
e_{t}=\sum D_{t}(i), \\
w_{t}=\frac{1}{2} \ln \left(\frac{1-e_{t}}{e_{t}}\right),
\end{array}\right.
$$

where $\sum D_{t}(i)$ is the weight of sample data, $e_{t}$ is the prediction error, and $w_{t}$ is the prediction weight. The next round of sample weight is adjusted according to the following equation:

$$
\begin{aligned}
D_{t+1}(i)= & \frac{D_{t}(i)}{C_{t}} * \exp \left[-w_{t} y_{i} g\left(x_{i}\right)\right], \\
& \cdot y_{i} \in Y=\{+1,-1\}, i=1,2 \ldots,
\end{aligned}
$$

where $C_{t}$ is the normalization factor, and $g\left(x_{i}\right)$ is the classifier function, after $t$ iterations. The strong predictor function $H(x)$ is the function combination of $t$ group weak predictor, which can be presented as follows: 


$$
H(x)=\left[\sum_{t=1}^{t} w_{t} \cdot f\left(g_{t}, w_{t}\right)\right] .
$$

For the GA-BP neural network model and BP-AdaBoost neural network model prediction results credibility, this study uses the root mean square error (RMSE) and mean absolute error (MAE) as the criteria. The smaller the index value is, the higher the prediction performance of the model is. For the comparison of prediction results between the GABP neural network model and BP-AdaBoost neural network model, this study takes the error sum and the absolute value of prediction error as the comparison standards. The smaller the index value is, the higher the prediction performance of the model is. In addition, the pseudocodes of the GA-BP neural network is presented in Algorithm 1, and the pseudocodes of the BP-AdaBoost neural network is presented in Algorithm 2.

2.2. Consumer Cost-Benefit Model. The low-carbon policies adopted in this study are carbon quota allocation, carbon tax, carbon trading, and emission reduction subsidy. Carbon quotas are targets for reducing greenhouse gas emissions that must be met. Carbon quota allocation is divided into free quota and paid quota. Carbon tax policy refers to a tax on carbon dioxide emissions. Carbon trading is a market trading mechanism that uses carbon dioxide emission as a commodity to reduce greenhouse gas emissions. Emission reduction subsidies are subsidies given by the government to private cars with a set standard of carbon emissions. Under different low-carbon policy mixes, the participation willingness of consumers, social benefits, and carbon emission reduction effect vary with consumers' own cost-benefit. Therefore, this study designs six kinds of low-carbon policy mixes to compare participation willingness, social benefits, and carbon emission reduction effect from the consumer perspective. Consumers' participation willingness is evaluated by their unit cost-benefit; the social benefits of consumers are evaluated by the difference between consumer benefits and costs; the emission reduction effect of policy implementation is evaluated by the difference between consumers' equilibrium emissions and actual emissions. The equilibrium emissions of consumers are the carbon emissions when the difference between consumer costs and benefits is zero.

Under the policy mix of free quota, carbon trading, and emission reduction subsidy, when the allocation method is free quota, consumers can get the free quota given by the government. In the actual emission process, consumers who exceed their quotas need to buy carbon emissions to meet their demands, while consumers who have surplus quotas sell carbon emissions to get benefits. Both of them complete this process by participating in carbon trading. In addition, the government will also subsidize private cars that produce less carbon per kilometer than required. Cost- benefit and emission reduction subsidies of consumers are as follows:

$$
\begin{aligned}
& \left\{\begin{array}{l}
R=\left(Q_{b}-Q_{s}\right) P_{c}+V_{b}, \\
C=Q_{s} P_{c}, \\
B_{1}=\frac{\left(Q_{b}-Q_{s}\right) P_{c}+V_{b}}{Q_{s} P_{c}},
\end{array}\right. \\
& V_{b}=\left(\partial-C_{d}\right) P_{c} L_{m} b_{t},
\end{aligned}
$$

where $R$ is the benefit obtained by consumers, $C$ is the cost paid by consumers, $B_{1}$ is the unit cost-benefit of consumers under the policy mix of free quota, carbon trading, and emission reduction subsidy, $Q_{b}$ is the free carbon emission of consumers, $Q_{s}$ is the actual carbon emission of consumers, $P_{c}$ is the carbon price, $V_{b}$ is emission reduction subsidy, $C_{d}$ is the carbon emissions per unit mile, $L_{m}$ is the driving mileage, $b_{t}$ is the subsidy rate, and $\partial$ is the standard of carbon emissions per mileage.

Under the free quota and carbon trading policy mix, consumers can get the free quota given by the government. In the actual emission process, both parties participate in carbon trading to buy and sell carbon emissions to meet their respective demands. Consumers are unable to obtain emission reduction subsidies, and the cost-benefit of consumers is as follows:

$$
B_{2}=\frac{\left(Q_{b}-Q_{s}\right) P_{c}}{Q_{s} P_{c}},
$$

where $B_{2}$ is the unit cost-benefit of consumers under the free quota and carbon-trading policy mix. Under the policy mix of free quota, carbon tax, and emission reduction subsidy, consumers can get free quotas and emit carbon dioxide while driving. Government imposes carbon tax to increase the travel cost of consumers, so as to promote the low-carbon emission reduction of consumers. In addition, the introduction of emission reduction subsidies can enhance consumers' emission reduction potential. The cost-benefit of consumer is as follows:

$$
\left\{\begin{array}{l}
R=V_{b}, \\
C=Q_{s} P_{c} T, \\
B_{3}=\frac{V_{b}}{Q_{s} P_{c} T},
\end{array}\right.
$$

where $T$ is the carbon tax rate, and $B_{3}$ is the unit cost-benefit of consumers under the policy mix of free quota, carbon tax, and emission reduction subsidy. From the perspective of free quota, carbon tax, and no emission reduction subsidy policy mix, consumers cannot obtain emission reduction subsidies $(R=0)$, so the unit cost-benefit of consumers $B_{4}$ is zero. 
Input: the training set $\left\{x_{s}, y_{s}, z_{s}\right\}$, the test set $\left\{x_{d}, y_{d}, z_{d}\right\}$. The maximum iteration value is $M$, the size population value is $N$, the crossover probability value is $\theta$, and the mutation probability value is $\beta$. The number of neuron nodes value is $N_{d}$.

Output: predicting the carbon emissions of private cars $\{y\}$

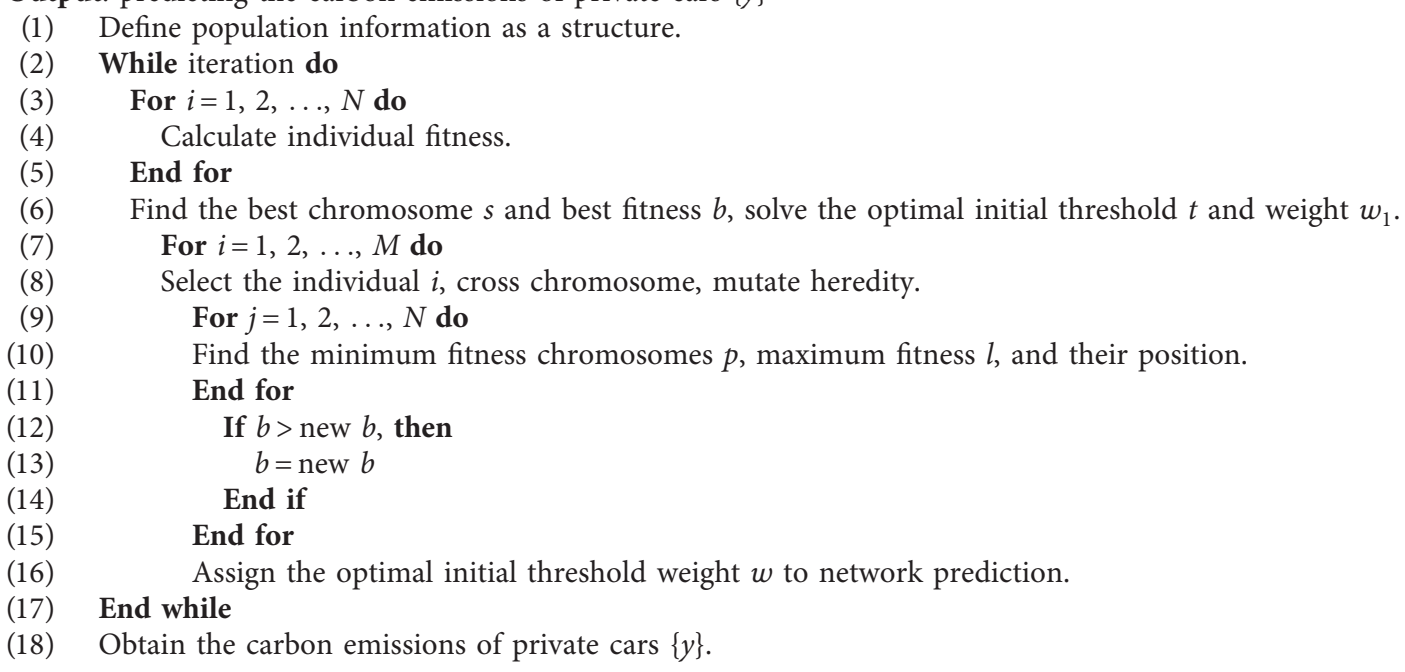

Algorithm 1: GA-BP genetic algorithm.

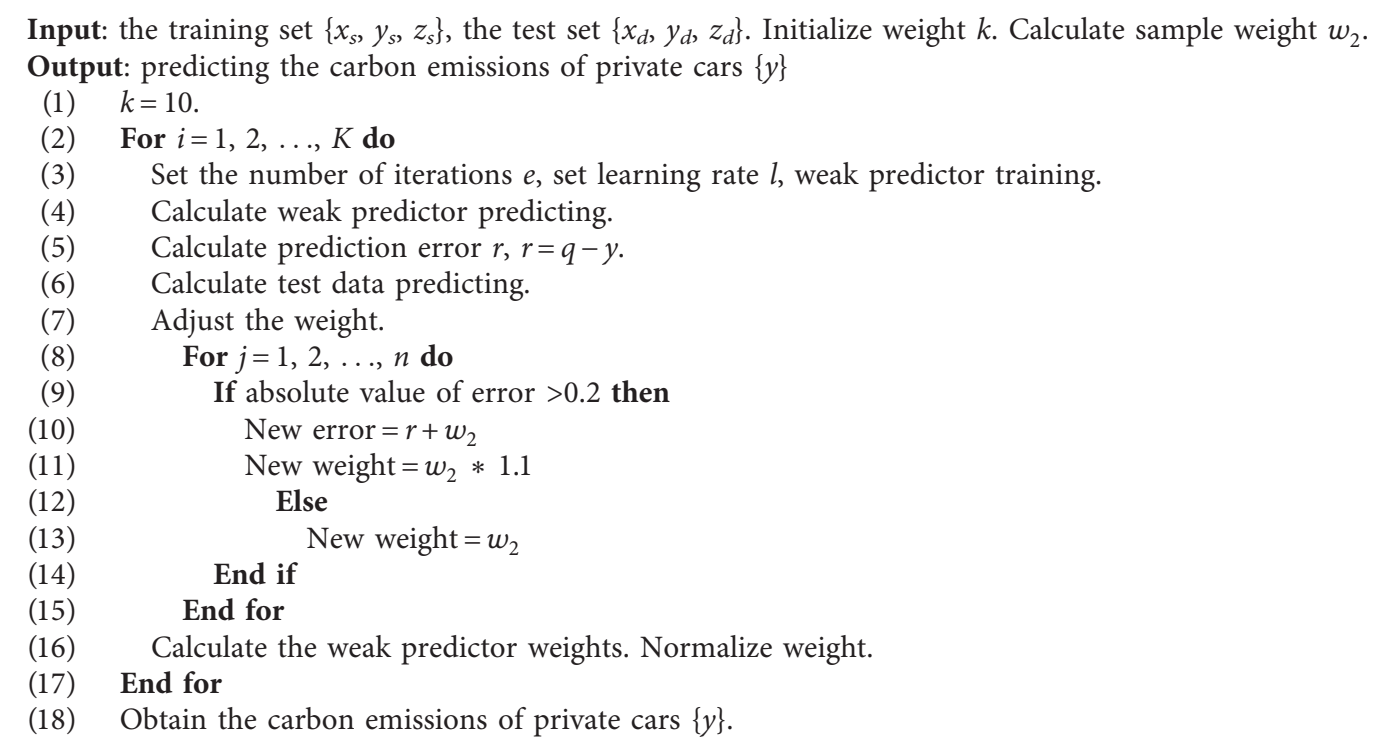

Algorithm 2: BP-AdaBoost adaptive boosting algorithm.

Under the policy mix of paid quotas, carbon-trading and emission reduction subsidies, consumers need to buy carbon credits from the government, participate in carbon trading, and receive carbon reduction subsidies. The quota method of paid quota increases the carbon cost of consumers, but emission reduction subsidy and carbon trading policy can enhance the enthusiasm of consumers. In the process of carbon trading, consumers can sell carbon quotas to get benefits, and private cars with lower carbon emissions can get benefits. The cost-benefit of consumer is as follows:

$$
\left\{\begin{array}{l}
R=\left(Q_{b}-Q_{s}\right) P_{c}+V_{b}, \\
C=\left(Q_{s}+Q_{b}\right) P_{c}, \\
B_{5}=\frac{\left(Q_{b}-Q_{s}\right) P_{c}+V_{b}}{\left(Q_{s}+Q_{b}\right) P_{c}},
\end{array}\right.
$$

where $B_{5}$ is the unit cost-benefit of consumers under the policy mix of paid quota, carbon trading, and emission reduction subsidy. Under the policy mix of paid quota, 
carbon trading, and no emission reduction subsidy, with the further increase of carbon cost, consumers can obtain demand through carbon trading in the actual emission process. The unit cost-benefit for consumer is as follows:

$$
B_{6}=\frac{\left(Q_{b}-Q_{s}\right) P_{c}}{\left(Q_{s}+Q_{b}\right) P_{c}},
$$

where $B_{6}$ is the unit cost-benefit of consumers under the policy mix of paid quota, carbon trading, and no emission reduction subsidy. From the perspective of paid quota, carbon tax, and emission reduction subsidy policy mix, consumers need to buy quotas from the government. The government also imposes carbon tax when consumers emit carbon dioxide, but the policy of emission reduction subsidy will reduce the carbon cost of consumers appropriately. The unit cost-benefit for consumer is as follows:

$$
\left\{\begin{array}{l}
R=V_{b}, \\
C=Q_{s} P_{c}(1+T), \\
B_{7}=\frac{V_{b}}{Q_{s} P_{c}(1+T)}
\end{array}\right.
$$

where $B_{7}$ is the unit cost-benefit of consumers under the policy mix of paid quota, carbon tax, and emission reduction subsidy. When consumers cannot obtain emission reduction subsidies, $R$ is zero. Therefore, the unit cost-benefit for consumer $B_{8}$ is 0 . In addition, the social benefits of consumer are calculated as the sum of $R-C$ differences. The emission reduction of consumer is calculated by the difference between the balance carbon emission and the actual carbon emission when $R-C$ is zero. The social benefits and emission reduction for consumers are as follows:

$$
\left\{\begin{array}{l}
T_{s}=\sum(R-C), \\
M_{s}=Q_{h}-Q_{S},
\end{array}\right.
$$

where $T_{s}$ is the social benefit, $M_{s}$ is the emission reduction, and $Q_{h}$ is the balance carbon emission.

\section{Results and Discussion}

3.1. Error Comparison between the Two Models. This study selects 10,000 urban private car trajectory data as the training set and test set according to the ratio of $7: 3$. Driving mileage, driving time, and driving fuel consumption are taken as the predictive variables of the neural network. By adjusting the number of neurons in the hidden layer, the error between the BP-AdaBoost neural network model and the BP-AdaBoost neural network model established in this study is given in Table 1 [1].

As given in Table 1, all indicators are optimal when the number of neurons is 10 in the GA-BP neural network model. Therefore, this study establishes a 3-10-1 GA-BP neural network model. In the BP-AdaBoost neural network model, all indicators are optimal when the number of neurons is 9. Therefore, this study establishes a 3-9-1
BP-AdaBoost neural network model. As shown in Figure 1 , this study takes 0.01 as a reasonable error range. When the error range is less than 0.01 , the number of errors of the GA-BP neural network is 1823, and the number of errors of the BP-AdaBoost neural network is 1654. In other error ranges, the number of errors of the GA-BP neural network is less than the BP-AdaBoost neural network; the GA-BP neural network is superior. In addition, the total error of GA-BP neural network prediction is 24.78 , the error rate is $0.25 \%$, the total error of BP-AdaBoost neural network prediction is 28.49 , and the error rate is $0.28 \%$. Therefore, the prediction result of the GA-BP neural network is better than that of the BPAdaBoost neural network overall.

3.2. Comparison of Simulation Results. In the error comparison, RMSE, MAE, and error sum of the GA-BP neural network model are smaller than those of the BP-AdaBoost neural network model. In addition, as shown in Figures 2 and 3, the prediction error of the GA-BP neural network model is within 0.03 , and the prediction error of the BPAdaBoost neural network model is within 0.35 . When the error range is less than 0.01 , the prediction accuracy of the GA-BP neural network is $60.77 \%$, while the prediction accuracy of the BP-AdaBoost neural network is only $55.13 \%$. When the error range is less than 0.25 , the prediction accuracy of the GA-BP neural network is $99.93 \%$, while the prediction accuracy of the BP-AdaBoost neural network is 97.87\%. In addition, the individual error of the GA-BP neural network is only 0.248 , while the individual error rate of the BP-AdaBoost neural network is 0.341 . Therefore, the prediction results of the GA-BP neural network are better. This study establishes a 3-10-1 GA-BP neural network model to simulate prediction.

The prediction results of simulation are given in Table 2; the expected carbon emissions are calculated by the IPCC calculation formula. The predicted carbon emissions are the prediction results of the neural network, and carbon emissions per unit mileage are the carbon emissions per unit kilometer of a private car. The emission reduction subsidy is calculated by formula (1).

In Table 2, the prediction error of the GA-BP neural network is less than 0.02 . The results are excellent. In addition, carbon emissions per mile exceed the specified emission standards that will not receive emission reduction subsidies. The emission reduction subsidies prescribed emission standards are given.

\section{The Comparison of the Policy Mix Implementation Effects from Consumer Perspective}

4.1. The Comparison of Consumers' Participation Willingness under Policy Mix. From the perspective of $B_{4}$ and $B_{8}$, the consumer's benefit and unit cost-benefit are 0 , which will not be drawn in this study. As shown in Figure 4, under the allocation of free quota, before carbon emissions reaches point $A$, the unit cost-benefit of consumer is optimal in the 
TABLE 1: Error comparison of the two models under the number of each neuron.

\begin{tabular}{|c|c|c|c|c|c|c|}
\hline Model/neural nu & & 7 & 8 & 9 & 10 & 11 \\
\hline \multirow{3}{*}{ GA-BP neural network } & RMSE & 0.0119 & 0.0102 & 0.0104 & 0.0094 & 0.01 \\
\hline & MAE & 0.0091 & 0.0083 & 0.0083 & 0.008 & 0.0082 \\
\hline & Error sum & 27.2044 & 24.7875 & 24.7823 & 24.0654 & 24.4685 \\
\hline \multirow{3}{*}{ BP-AdaBoost neural network } & RMSE & 0.0156 & 0.0128 & 0.0118 & 0.0204 & 0.1084 \\
\hline & MAE & 0.0105 & 0.0097 & 0.0095 & 0.0122 & 0.0144 \\
\hline & Error sum & 31.3554 & 28.9729 & 28.4914 & 36.6374 & 43.3059 \\
\hline
\end{tabular}

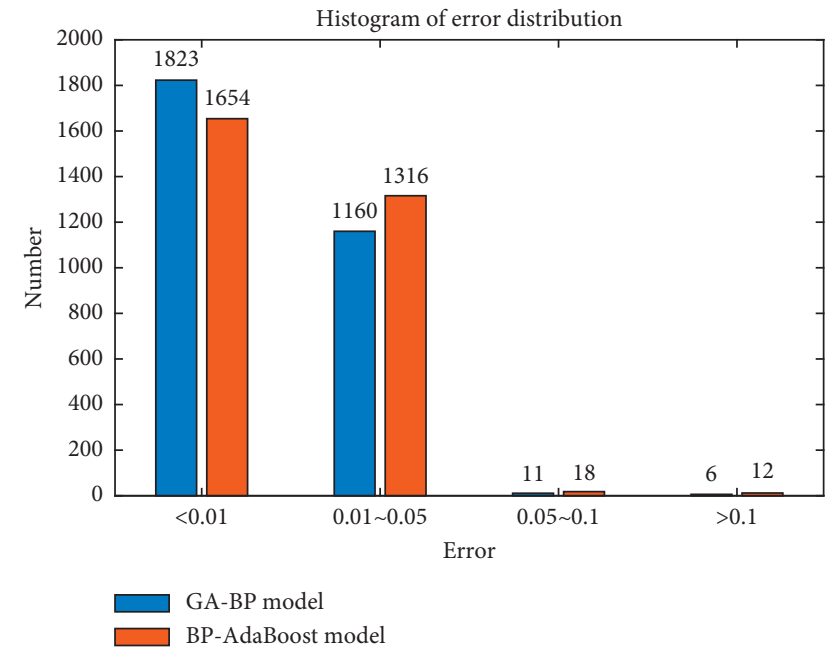

Figure 1: The comparison of error distribution between the two models.

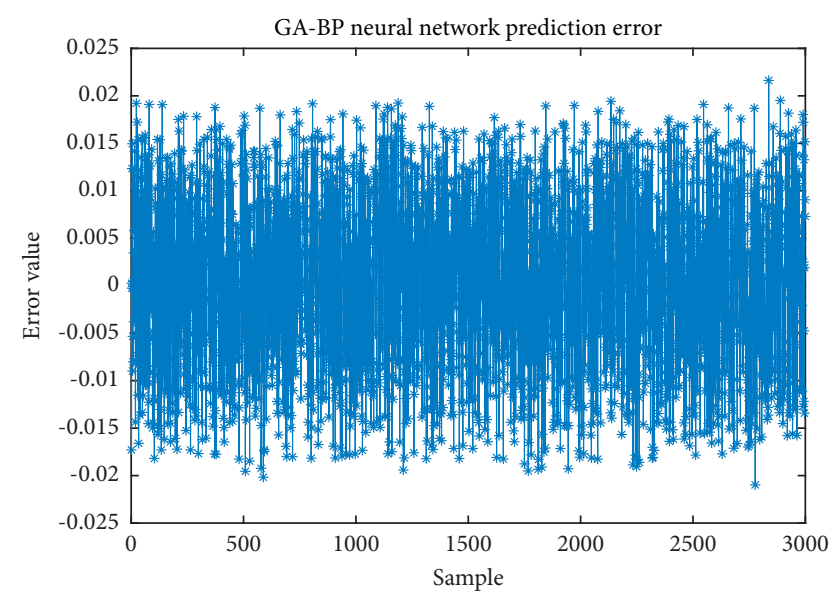

Figure 2: Prediction error of the GA-BP model.

$B_{1}$ mix; after the carbon emissions reaches point $A$, the unit cost-benefit of consumer is optimal in the $B_{2}$ mix, and the consumer's participation willingness is the highest. Under the allocation of paid quota, before carbon emissions reach point $B$, the unit cost-benefit of consumer is optimal in the $B_{7}$ mix. When the carbon emissions are between point $B$ and point $C$, the unit cost-benefit of consumer is optimal in the $B_{5}$ mix; after the carbon emissions reaches point $C$, the unit cost-benefit of consumer is optimal in the $B_{6} \mathrm{mix}$, and the consumer's participation willingness is the highest. Overall,

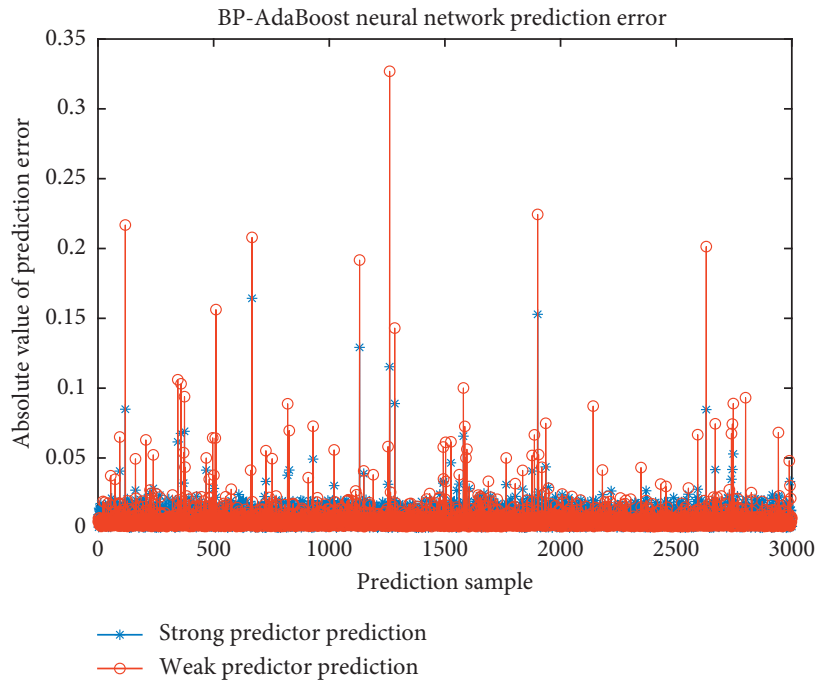

Figure 3: Prediction error of the BP-AdaBoost model.

when carbon emissions continue to increase, the unit costbenefit of consumer is optimal, and the consumer's participation willingness is the highest in the $B_{2}$ mix.

\subsection{The Comparison of the Consumers' Emission Reduction} Effect under Policy Mix. As shown in Figure 5, when the lowcarbon policy is paid quota, the emission reduction effect of consumer is optimal in the $B_{7}$ mix, which is always higher than the mix of $B_{5}$ and $B_{6}$. When the low-carbon policy is free quota, the emission reduction effect of consumer from the perspectives of $B_{1}, B_{2}$, and $B_{3}$ is different. Overall, the emission reduction effect of consumers under the mix of free quota is always better than the mix of paid quota. Before the driving mileage reaches point $D$, the emission reduction effect of consumer is optimal in the $B_{2}$ mix. When the driving mileages are between point $D$ and point $E$, the emission reduction effect of consumer is optimal in the $B_{1}$ mix. After the driving mileage reaches point $E$, the emission reduction effect of consumer is optimal in the $B_{3}$ mix.

4.3. The Comparison of Consumers' Social Benefits under Policy Mix. As shown in Figure 6, before the carbon emission reaches point $F$, the social benefits of consumer are optimal in the $B_{1}$ mix. When the carbon emission is between point $F$ and point $G$, the social benefits of consumer are optimal in the $B_{2}$ mix. After the carbon emission reaches point $G$, the social benefits of consumer are optimal in the $B_{3}$ 
TABle 2: Prediction results of the GA-BP neural network and subsidy amount.

\begin{tabular}{|c|c|c|c|c|c|c|}
\hline S/no. & Driving mileage & Expected carbon emissions & Projected carbon emissions & Error & Carbon emissions per unit mileage & Subsidy \\
\hline 1 & 8.9 & 3.21 & 3.19 & -0.02 & 0.36 & 0 \\
\hline 2 & 2.01 & 0.89 & 0.89 & 0 & 0.44 & 0 \\
\hline 3 & 13.14 & 4.58 & 4.57 & -0.01 & 0.35 & 0 \\
\hline 4 & 23.89 & 5.74 & 5.74 & 0 & 0.24 & 0.43 \\
\hline 5 & 5.94 & 2.41 & 2.43 & 0.02 & 0.41 & 0 \\
\hline ... & $\cdots$ & $\cdots$ & $\cdots$ & $\cdots$ & $\cdots$ & $\ldots$ \\
\hline$\ldots$ & $\ldots$ & $\ldots$ & $\ldots$ & $\ldots$ & $\ldots$ & $\ldots$ \\
\hline$\ldots$ & $\ldots$ & $\ldots$ & $\ldots$ & $\ldots$ & $\ldots$ & $\ldots$ \\
\hline 2999 & 1.81 & 0.74 & 0.74 & 0 & 0.41 & 0 \\
\hline 3000 & 31.26 & 6.73 & 6.72 & -0.01 & 0.21 & 0.84 \\
\hline
\end{tabular}

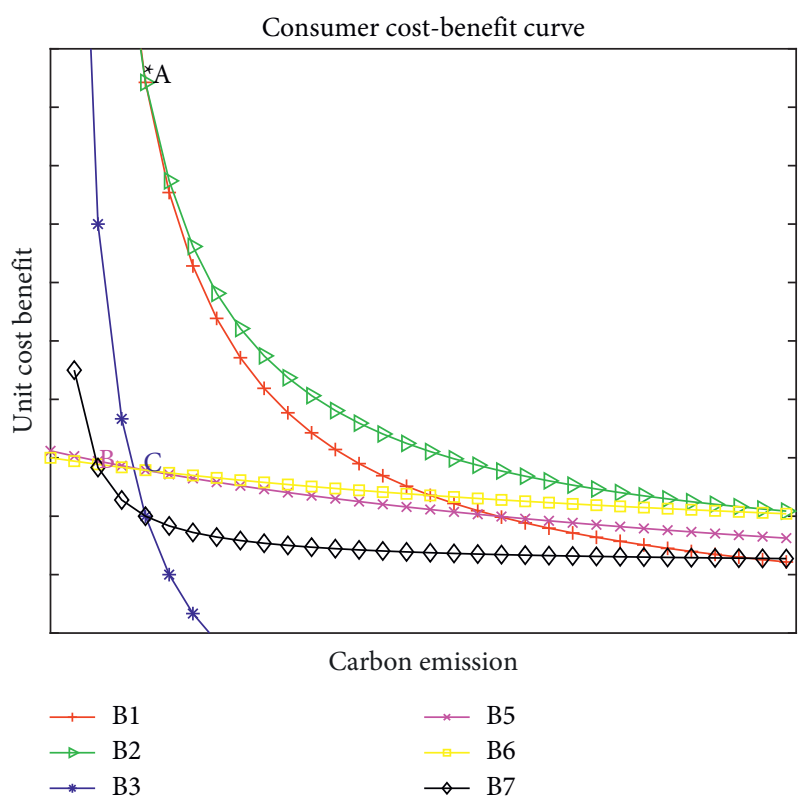

FIgURE 4: The comparison of participation willingness.

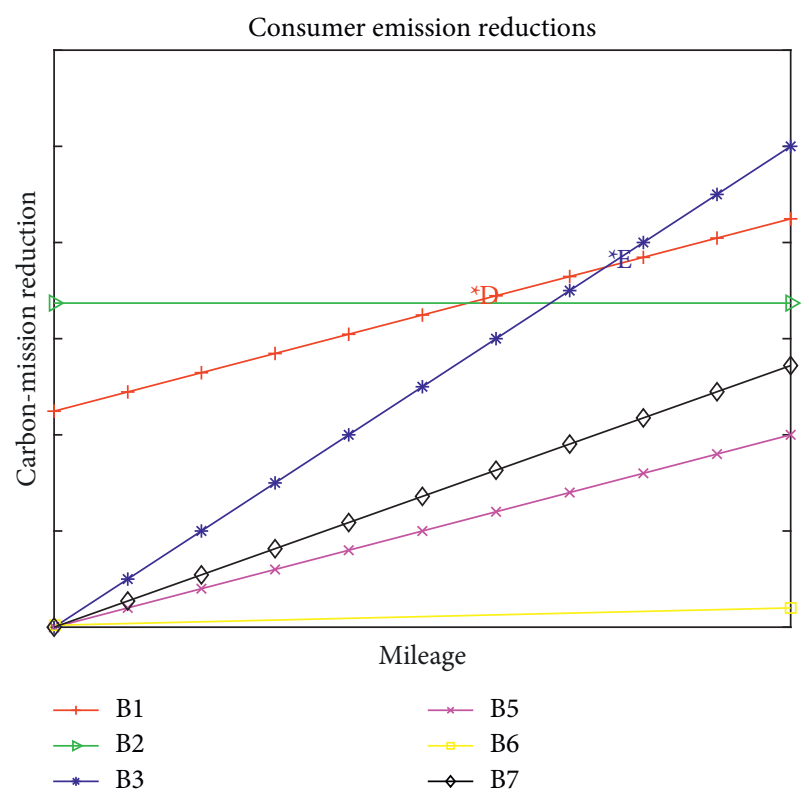

Figure 5: The comparison of the emission reduction effect.

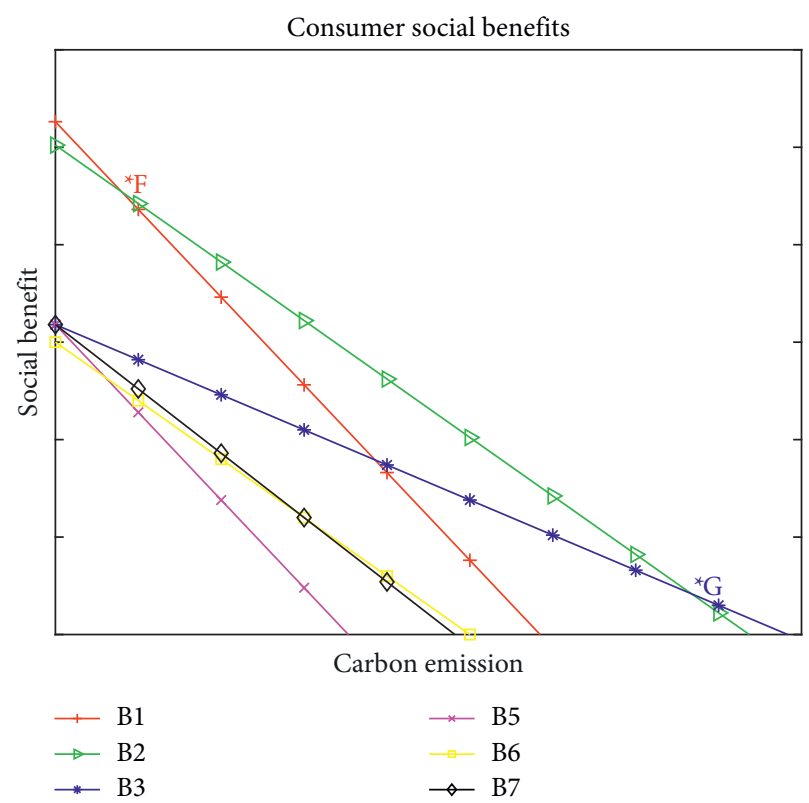

Figure 6: The comparison of social benefits.

mix. The social benefits of consumer under the paid quota policy mix are different. In general, the social benefits of consumer under the free quota policy mix is obviously better than the paid quota policy mix.

\section{Conclusions}

Based on urban private cars trajectory data, this study establishes the GA-BP neural network model and BP-AdaBoost neural network model for simulation comparison and finds that the prediction results of the GA-BP neural network model are more accurate. In addition, based on the prediction results of the GA-BP neural network model, this study compares consumers' participation willingness, emission reduction effect, and social benefits under multiple low-carbon policy mix innovation scenarios and finds that the policy mix of free quota is better than that of paid quota in these respects. As for the participation willingness of consumers, the mix of carbon trading and emission reduction subsidy has the best unit cost-benefit and the highest consumers' participation willingness in the short term; the mix of carbon trading and no emission reduction subsidy is 
better in the long term. As for the effect of emission reduction, the policy mix of carbon trading and zero emission reduction subsidy will result in a better emission reduction effect for consumers in the short term; the policy mix of carbon tax and emission reduction subsidy is better in the long term. As for the social benefits of consumers, the policy mix of carbon trading and emission reduction subsidy will bring the best social benefits in the short term; the policy mix of carbon tax and emission reduction subsidy has better social benefits in the long term. Therefore, from the perspective of different indicators, the policy implementation effects of low-carbon policy mix are different, and it is better to implement carbon trading policy in the short term and carbon tax policy in the long term.

This study combines five low-carbon policies and incorporates them into the framework of carbon emission reduction for private cars, quantitatively compares consumers' participation willingness, emission reduction effect and social benefits under multiple low-carbon policy mix innovation, and provides policy ideas for emission reduction of private cars in smart city.

In order to build a smart city with sustainable development and smoothly achieve carbon peak and carbon neutrality, it is necessary to implement carbon emission reduction schemes for road transportation. Based on the low-carbon policy mix innovation proposed in this study, relevant policy proposals can be started from the following aspects: (1) preferential application of the policy mix of free quota. The policy mix of free quota can encourage consumer participation and increase emissions reduction. In the empirical study of this study, the policy mix of free quota is superior to that of paid quota. (2) Carbon trading policy will be implemented in the short term, carbon tax policy will be implemented in the long term, and a proper policy mix of emission reduction subsidy will be adopted in due course. Carbon trading policy has low social cost and high implementation cost, and consumers are more willing to participate in the short term, while carbon tax policy has high social cost and low implementation cost. In the long run, it will further reduce carbon emissions. Timely innovation and adoption of low-carbon policy mix can enhance consumers' participation willingness and emission reduction effect [33]. (3) Considering the emission reduction path under multiple low-carbon policy mixes innovation, the low-carbon policy mix can be combined with the market-based low-carbon policy and the commandand-control low-carbon policy to promote carbon emission reduction of urban private cars.

\section{Data Availability}

The data used to support the findings of this study have not been made available because of the confidentiality agreements with research collaborators. The data form part of an ongoing commercial program and study.

\section{Conflicts of Interest}

The authors declare that they have no conflicts of interest.

\section{Acknowledgments}

This study was supported by Low-Carbon Transition Path and Policy Mix Innovation Based on Green Governance, National Social Science Foundation of China (19CGL043).

\section{References}

[1] J. Zhong, Y. Lin, and S. Yang, "The impact of ride-hailing services on private car use in urban areas: an examination in Chinese cities," Journal of Advanced Transportation, vol. 2020, Article ID 8831674, 15 pages, 2020.

[2] Y. F. Chen and C. Y. Liu, "Discussion on the initial allocation mechanism of carbon emission trading quota," Cooperative Economy and Science and Technology, vol. 4, pp. 88-89, 2019.

[3] X. B. Pan and X. Y. Shi, "Construction of free allocation system of carbon emission trading quota," Journal of Tianjin University, vol. 18, no. 4, pp. 338-343, 2016.

[4] Q. Wei, Y. Pan, L. J. Lin et al., "A comparative study on enterprise emission reduction and social welfare under carbon quota and subsidy policy," Southern Finance, vol. 2, pp. 25-37, 2021.

[5] X. Zhang, X. X. Shao, H. Q. Jiang et al., "Initial quota allocation of industrial carbon emission rights -- literature review," Resources development and market, vol. 31, no. 11, pp. 1520-1525, 2018.

[6] Y. H. Miao, Study on Optimization System of Carbon Emission Reduction Cost in Guangdong Province under Non-free Carbon Quota, North China Electric Power University, Beijing, China, 2019.

[7] G. H. Li, "Research on the mechanism of carbon emission Trading quota auction," China Engineering Consulting, vol. 5, pp. 43-45, 2016.

[8] X. W. Xuan and H. Zhang, "International experience and enlightenment of carbon emission quota allocation," China population, resources and environment, vol. 23, no. 12, pp. 10-15, 2013.

[9] D. Ding and J. R. Feng, "Selection of carbon trading quota allocation in China," International Business, vol. 4, pp. 83-92, 2013.

[10] D. B. Hu, L. N. Peng, X. H. Chen et al., "Research on the impact of quota allocation mode on the operational efficiency of carbon trading market in different regions," Science and technology management research, vol. 38, no. 19, pp. 240-246, 2018.

[11] J. Wu, Y. Fan, Y. Xia et al., "The impact of initial allocation of carbon quota on macro-economy and industry competitiveness of Provinces in China," Management Review, vol. 27, no. 12, pp. 18-26, 2015.

[12] Y. Shikha and K. Aditi, "Sustainable inventory model for perishable products with expiration date and price reliant demand under carbon tax policy," Process Integration and Optimization for Sustainability, vol. 5, pp. 1-12, 2021.

[13] A. Baranzini, J. Goldemberg, and S. Speck, "A future for carbon taxes," Ecological Economics, vol. 32, no. 3, pp. 395-412, 2000.

[14] M. Botteon and C. Carraro, "Is the European carbon tax really effective?" The European Carbon Tax: An Economic Assessment, vol. 1, pp. 255-284, 1993.

[15] Y. Li, W. Z. Shi, and Z. Y. Hu, "Research on double dividend effect of carbon tax policy based on CGE model," Financial Theory \& Practice, vol. 42, no. 4, pp. 82-89, 2021. 
[16] Z. G. Li, J. Wang, and S. Che, "Synergistic effect of carbon trading scheme on carbon dioxide and atmospheric pollutants," Sustainability, vol. 13, no. 10, pp. 5401-5403, 2021.

[17] Z. L. Lu and Y. S. Luo, "Analysis on the effectiveness of carbon trading policy in China -- Application and test of double difference method," Resources and environment in arid areas, vol. 34, no. 4, pp. 1-7, 2020.

[18] H. L. He and Y. X. Yue, "Strategic environmental policy: a comparative analysis of environmental taxes and emission reduction subsidies," Journal of Finance and Economics, vol. 2, pp. 136-143, 2009.

[19] A. H. Wang, L. B. Huang, Y. Y. He et al., "Research on competition and cooperation game of mixed duopoly enterprises under carbon tax and emission reduction subsidy," Industrial Engineering, vol. 23, no. 2, pp. 9-18, 2020.

[20] X. W. Diao, Z. X. Zeng, and C. Sun, "Technology selection strategy of manufacturers' low-carbon transition under mixed carbon policy," Control and Decision, vol. 36, no. 7, pp. 1763-1770, 2021.

[21] L. Wang, M. Wang, and K. K. Lin, "Analysis of the impact of different composite carbon policy combinations on the decision-making of heterogeneous supply chain," Industrial Engineering \& Management, vol. 25, no. 1, pp. 60-68, 2020.

[22] W. C. Ma, Y. P. Ye, and X. D. Chen, "Innovation policy mix: research review and future prospect," Science and Technology Progress and countermeasures, vol. 37, no. 15, pp. 152-160, 2020.

[23] M. Howlett and J. Rayner, "Patching vs packaging in policy formulation: assessing policy portfolio design," Politics and Governance, vol. 1, no. 2, pp. 170-182, 2013.

[24] I. Maria and B. Freitas, "Mapping variety of innovation strategies sponsored by the policy-mix: an analytical framework and an empirical exploration," Journal of Evolutionary Economics, vol. 30, no. 3, pp. 741-771, 2020.

[25] K. S. Rogge and K. Reichardt, "Policy mixes for sustainability transitions: an extended concept and framework for analysis," Research Policy, vol. 45, no. 8, pp. 1620-1635, 2016.

[26] S. R. Karoline and J. Schleich, "Do policy mix characteristics matter for low-carbon innovation? A survey-based exploration of renewable power generation technologies in Germany," Research Policy, vol. 47, no. 9, pp. 1639-1654, 2018.

[27] V. Costantini, F. Crespi, and A. Palma, "Characterizing the policy mix and its impact on eco-innovation: a patent analysis of energy-efficient technologies," Research Policy, vol. 46, no. 4, pp. 799-819, 2017.

[28] Z. Chu, M. W. Cheng, and N. N. Yu, "A smart city is a less polluted city," Technological Forecasting and Social Change, vol. 172, Article ID 121037, 2021.

[29] D. Q. Shi, H. Ding, P. Wei et al., "Can smart city construction reduce environmental pollution?" China Industrial Economics, vol. 6, pp. 117-135, 2018.

[30] M. Julien, "Inclusive smart cities: beyond voluntary corporate data sharing," Sustainability, vol. 13, no. 15, 2021.

[31] T. J. Tan, Z. Yang, F. Chang, and Z. Xing, "Prediction of the first weighting from the working face roof in a coal mine based on a GA-BP neural network," Applied Sciences, vol. 9, no. 19, 2019.

[32] R. Yang, "Enterprise network marketing prediction using the optimized GA-BP neural network," Complexity, vol. 2020, pp. 1-9, Article ID 6682296, 2020.

[33] X. Li, L. Gao, and J. Liu, "The approach to carbon emission quotas of road transportation: a carbon emission intensity perspective," Journal of Advanced Transportation, vol. 2020, pp. 1-18, Article ID 8819694, 2020. 